\title{
Phenotype distribution of the paraoxonase gene in patients with cardiac disease
}

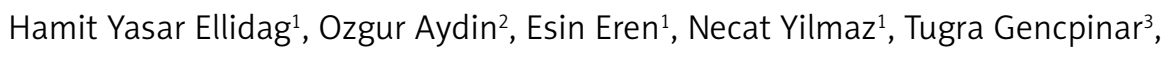
Selcuk Kucukseymen ${ }^{4}$, Akar Yilmaz ${ }^{4}$, Fatma Demet Arslan Ince ${ }^{5}$

${ }^{1}$ Department of Biochemistry, Antalya Education and Research Hospital, Antalya, Turkey

${ }^{2}$ Biochemistry Laboratory, Maternity and Children's Hospital, Batman, Turkey ${ }^{3}$ Cardiovascular Surgery Clinic, Education and Research Hospital, Antalya, Turkey ${ }^{4}$ Clinic of Cardiology, Antalya Education and Research Hospital of Ministry of Health, Antalya, Turkey

${ }^{5}$ Department of Biochemistry, Tepecik Education and Research Hospital of Ministry of Health, Izmir, Turkey

Submitted: 12 April 2015

Accepted: 5 June 2015

Arch Med Sci 2017; 13, 4: 820-826

DOI: https://doi.org/10.5114/aoms.2016.59674

Copyright $\odot 2016$ Termedia \& Banach

\section{Abstract}

Introduction: Paraoxonase (PON1) is an enigmatic enzyme with multiple enzymatic properties including arylesterase and lactonase activities besides its ability to hydrolyze the toxic metabolite of parathion, paraoxon. The aim of this study was to determine the phenotype distribution of PON1 in patients with cardiac disease who were classified in coronary artery bypass grafting (CABG), heart valve disease (HVD), heart failure (HF) and ST elevation myocardial infarction (STEMI) groups and healthy subjects as a control group. Material and methods: A total of 300 people (100 cardiac surgery (70 CABG and $30 \mathrm{HVD}$ ), $70 \mathrm{HF}, 30$ STEMI patients and 100 healthy controls) were admitted to this study. Individual variations in PON1 were determined using the dual substrate (paraoxon and phenylacetate) method.

Results: The following phenotype distributions were found in the cardiac disease and control groups: cardiac disease group $(n=200): 48.5 \%(Q Q)$, $42.5 \%(\mathrm{QR}), 9 \%(\mathrm{RR})$ and control group $(n=100): 58 \%(\mathrm{QQ}), 39 \%(\mathrm{QR}), 3 \%$ (RR). RR (high activity) phenotypic distribution was more common in the cardiac disease group than in controls $(p=0.04)$. In particular, the frequency of the RR phenotype was two- to three-fold higher in the STEMI and HF patients compared to the controls as well as CABG and HVD groups.

Conclusions: We found a higher percentage of RR phenotype in STEMI and $\mathrm{HF}$ patients compared to a large control group as well as compared to two other groups of cardiac disease patients.

Key words: arylesterase, heart diseases, lipids, high-density lipoprotein, oxidative stress.

\section{Introduction}

Atherosclerosis and related diseases such as angina pectoris (AP), acute myocardial infarction (AMI) and heart failure (HF) are the leading causes of death in older adults [1]. Studies have demonstrated that cardiovascular disease (CVD) is the cause of death in 30\% of all mortalities reported in the USA $[2,3]$. The mortality risk of CVD depends

\author{
Corresponding author: \\ Hamit Yasar Ellidag \\ Antalya Education \\ and Research Hospital \\ Varlik Mahallesi \\ Kazim Karabekir \\ Caddesi Soguksu 07100 \\ 07100 Antalya, Turkey \\ Phone: +905054952155 \\ E-mail: hayael1980@ \\ hotmail.com
}


on gender, age, smoking, systolic blood pressure, total cholesterol, and high-density lipoprotein (HDL) cholesterol [1]. High density lipoprotein has been demonstrated to have a diversity of functions which may contribute to its cardiovascular defensive effects, including reverse cholesterol transport, anti-inflammatory and antioxidative effects [4-6]. Paraoxonase-1 (PON1) is a HDL-associated multifunctional (esterase/lactonase) enzyme, which protects cells against oxidative damage. Studies indicate that the arylesterase (ARE) activity best reflects the antioxidant activity of PON1. PON1 and ARE inhibit low-density lipoprotein (LDL) oxidation and significantly mitigate the lipid peroxidase enzyme, which reduces the amassing of cholesterol in peripheral tissues $[7,8]$.

The paraoxonase-1 (PON1) gene is located on chromosome 7q21.3. Due to a polymorphism in this gene, PON1 activity in reactions that use paraoxon as a substrate varies from 10- to 40fold between individuals, but ARE does not show such a polymorphism [9]. PON1 has significant common functional genetic polymorphisms in the coding region of the gene at codons 55 and $192[10,11]$. The supersession of glutamine (Q genotype) at codon 192 in exon 6 of the PON1 gene by arginine ( $R$ genotype) is the primary polymorphism. Likewise, supersession of leucine (L genotype) at codon 55 in exon 3 by methionine ( $M$ genotype) is the second polymorphism. The PON1 activity of PON1 192 R allele bearers was demonstrated to be higher than that of the $\mathrm{Q}$ carriers. Human paraoxonase therefore has three phenotypes: RR with high paraoxonase activity, QR with intermediate activity, and QQ with low activity [12, 13].

Many studies have evaluated PON1 levels in heart disease, but data on PON1 phenotypes in patients with heart disease are contradictory. The aim of this study was to determine the phenotype distribution and enzymatic activity of PON1 and ARE in four different classes of cardiac disease patients, namely the cardiac surgery group (coronary artery bypass grafting (CABG), heart valve disease (HVD)), heart failure (HF) and ST elevation myocardial infarction (STEMI) patients, and compare them with healthy subjects.

\section{Material and methods}

\section{Subjects}

A total of 300 subjects (100 cardiac surgery, $70 \mathrm{HF}, 30$ STEMI patients and 100 healthy control patients) were admitted to this study. We used a questionnaire that included questions on demographics, diet, and other lifestyle factors. In light of this questionnaire, we included patients with a similar diet and lifestyle.

\section{Cardiac surgery group (CABG and HVD)}

The study subjects (CABG: 70, HVD: 30 (mitral valve disease: 25 , aortic valve disease: 5 )) were selected from individuals who were candidates for open heart surgery and had proven coronary artery disease (CAD) or HVD. The indication for coronary revascularization and the type of surgery (off-pump and on-pump (ABG) was determined by the clinical judgment of the attending cardiac surgeon. Preoperative blood samples were taken from the patients. Typically, these patients do not have the same profile of traditional coronary risk factors as CAD patients.

\section{Heart failure group}

The study included 70 consecutive subjects with heart failure (all of ischemic origin and with a left ventricular ejection fraction (LVEF) $<45 \%$ ) as determined by echocardiography. The patients included were also suffering from clinical heart failure as diagnosed by the treating HF specialist in the cardiology center. Patients were classified according to the New York Heart Association classification, as class II, III, and IV on submission. Eighteen patients in class II, 32 patients in class III, and 20 patients in class IV were each enrolled in the study group.

\section{ST elevation MI group}

Thirty consecutive male patients were enrolled in this study with acute STEMIs. These patients were admitted to our hospital with chest pain, and underwent cardiac catheterization. The patients presented within $12 \mathrm{~h}$ of the onset of symptoms (typically, chest pain lasting for $>30 \mathrm{~min}$ ), and had ST-segment elevation $\geq 0.2 \mathrm{~mm}$ in contiguous electrocardiographic leads or a new onset of complete left bundle-branch block. They each had primary percutaneous coronary intervention (PCl; angioplasty and/or stent deployment). Blood samples were obtained after $\mathrm{PCl}$.

\section{Control group}

One hundred healthy volunteers were also recruited as a normal control group. The control subjects underwent a full clinical examination by a physician, and a careful medical history was recorded for all of these subjects. None of the control subjects exhibited any symptoms or had any signs of CVD. These subjects had no other apparent major disease. Information on the smoking habits and any drug treatments of patients was obtained via a questionnaire.

The study exclusion criteria for the groups were: vitamins or dietary supplements, pregnancy, malignant disease, chronic pulmonary obstructive disease, overt clinical features of infection or chronic inflammatory disease. 
The study was approved by the local Ethical Committee, and all the recruited subjects signed informed consent to participate in the study.

\section{Measurement of paraoxonase and arylesterase enzyme activities in serum}

PON1 and ARE enzyme activities were measured using commercially available kits (Relassay, Turkey). The fully automated PON1 activity measurement method consists of two different sequential reagents; the first reagent is an appropriate Tris buffer containing calcium ions, which is a cofactor of PON1 enzyme. A linear increase in the absorbance of $p$-nitrophenol, produced from paraoxon, is followed in a kinetic measurement mode. The non-enzymatic hydrolysis of paraoxon was subtracted from the total rate of hydrolysis. The molar absorptivity of p-nitrophenol is 18,290 $\mathrm{M}^{-1} \mathrm{~cm}^{-1}$, and one unit of paraoxonase activity is equal to $1 \mathrm{~mol}$ of paraoxon hydrolyzed per liter per minute at $37^{\circ} \mathrm{C}$ [14]. Phenylacetate was used as a substrate to measure ARE activity. PON1, present in the sample, hydrolyses phenylacetate to its products, phenol and acetic acid. The produced phenol is colorimetrically measured via oxidative coupling with 4-aminoantipyrine and potassium ferricyanide. Nonenzymatic hydrolysis of phenyl acetate was then subtracted from the total rate of hydrolysis. The molar absorptivity of the colored complex is $4000 \mathrm{M}^{-1} \mathrm{~cm}^{-1}$, and $1 \mathrm{U}$ of arylesterase activity is equal to $1 \mathrm{mmol}$ of phenylacetate hydrolyzed per liter per minute at $37^{\circ} \mathrm{C}$ [15].

\section{Paraoxonase phenotype distribution}

The genetic polymorphism Q/R in codon 192 is responsible for three isotypes: QQ (low activity), QR (intermediate activity), and RR (high activity). The phenotype distribution of PON1 was determined using the dual substrate method. The ratio of paraoxon hydrolysis in the presence of $1 \mathrm{~mol} / \mathrm{l}$ $\mathrm{NaCl}$ (salt-stimulated paraoxonase: stPON) to phenylacetate hydrolysis was used to assign individuals to one of the phenotypes [14]. The ratio provided by dividing salt-stimulated paraoxonase by arylesterase enzyme activity demonstrated a trimodal PON1 frequency distribution in the whole study population (Figure 1). Accordingly, the cut-off values for assigning a participant to a phenotype were $<2.0$ for QQ, 2.0 to 5.0 for $\mathrm{QR}$ and $>5.0$ for $\mathrm{RR}$. Allele $\mathrm{Q}$ and allele $\mathrm{R}$ were in excellent agreement with the Hardy-Weinberg equilibrium (Figure 1).

\section{Routine parameters}

The levels of triglycerides (TG), total cholesterol (TC), HDL cholesterol and LDL cholesterol were determined by using commercially available assay kits (Abbott) with an autoanalyzer (Architect c16000, Abbott Diagnostics).

\section{Statistical analysis}

Statistical analyses were carried out using the statistical software MedCalc version 11.5.1.0 (MedCalc, Mariakerke, Belgium). The Kolmogorov-Smirnov test was used to determine normal-

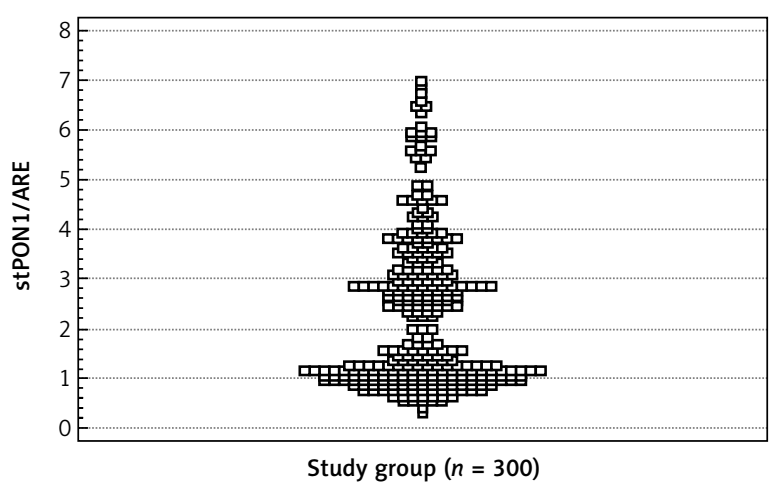

Hardy-Weinberg equilibrium for whole study population

\begin{tabular}{lcccc}
\hline $\begin{array}{l}\text { Observed number of individuals } \\
\text { with each phenotype* }\end{array}$ & $\begin{array}{c}\text { Observed allele } \\
\text { frequencies }\end{array}$ & $\begin{array}{c}\text { Expected genotype } \\
\text { frequency }\end{array}$ & $\begin{array}{c}\text { Expected number } \\
\text { of population }\end{array}$ & $\begin{array}{c}\text { Observed-expected } \\
\text { population }\end{array}$ \\
\hline Phenotype-QQ $=155(\%)$ & Allele $(p)=0.723$ & $p^{2}=0.523$ & 156.9 & -1.9 \\
\hline Phenotype-QR $=124(\%)$ & Allele $(q)=0.277$ & $2 p q=0.4$ & 120 & 4 \\
\hline Phenotype-RR $=21(\%)$ & & $q^{2}=0.077$ & 23.1 & -2.1 \\
\hline Whole study population $=300$ & $\begin{array}{c}\text { Hardy-Weinberg } \\
\text { equilibrium: }\end{array}$ & $p^{2}+2 p q+q^{2}=1$ & & $x^{2}=0$ NS \\
\hline
\end{tabular}

${ }^{*}$ Based on stPON1/ARE (dual substrate method): the cut-off values for assising a participant to a phenotype were $<2.0$ for $Q Q, 0.0$ to 5.0 for $Q R$ and > 5.0 for RR. NS - non-significant.

Figure 1. Distribution of PON1 phenotype in whole study group and Hardy-Weinberg equilibrium 
Table I. Laboratory findings and demographic characteristics of cardiac disease patients and healthy controls

\begin{tabular}{|c|c|c|c|c|c|c|}
\hline Parameters & $\begin{array}{c}(a) \\
\text { CABG } \\
(n=70)\end{array}$ & $\begin{array}{c}\text { (b) } \\
\text { HVD } \\
(n=30)\end{array}$ & $\begin{array}{c}(c) \\
\mathrm{HF} \\
(n=70)\end{array}$ & $\begin{array}{c}(d) \\
\text { STEMI } \\
(n=30)\end{array}$ & $\begin{array}{c}(\mathrm{e}) \\
\text { Control } \\
(n=100)\end{array}$ & $P$-value \\
\hline Age [years] ${ }^{*}$ & $59.8 \pm 13$ & $53 \pm 20$ & $69.4 \pm 12$ & $56.2 \pm 14$ & $54 \pm 10$ & $<0.01$ \\
\hline Males** & $48(68 \%)$ & $17(57 \%)$ & 54 (71.1\%) & $30(100 \%)$ & $52(52 \%)$ & 0.02 \\
\hline Smokers & $33(47 \%)$ & $12(40 \%)$ & $25(36 \%)$ & $14(47 \%)$ & $32(32 \%)$ & 0.20 \\
\hline BMI $\left[\mathrm{kg} / \mathrm{m}^{2}\right]$ & $28.1 \pm 4.2$ & $26.5 \pm 3.7$ & $27.6 \pm 4.34$ & $27.4 \pm 3.1$ & $26.9 \pm 5.2$ & 0.09 \\
\hline $\mathrm{TC}^{\prime}[\mathrm{mg} / \mathrm{dl}]$ & $181 \pm 45$ & $161 \pm 39$ & $164 \pm 41$ & $168 \pm 19$ & $166 \pm 33$ & 0.01 \\
\hline $\mathrm{TG}^{\# \#[\mathrm{mg} / \mathrm{dl}]}$ & $167 \pm 105$ & $103 \pm 45$ & $98 \pm 42$ & $145 \pm 42$ & $130 \pm 57$ & 0.03 \\
\hline $\left.\mathrm{HDL}^{\dagger} \mathrm{mg} / \mathrm{dl}\right]$ & $37 \pm 11$ & $35 \pm 13$ & $35 \pm 12$ & $36 \pm 11$ & $46 \pm 11$ & $<0.01$ \\
\hline 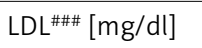 & $115 \pm 51$ & $109 \pm 45$ & $107 \pm 34$ & $103 \pm 40$ & $101 \pm 29$ & 0.08 \\
\hline $\mathrm{PON1}^{+\dagger}[\mathrm{U} / \mathrm{I}]$ & $127 \pm 78$ & $119 \pm 79$ & $110 \pm 74$ & $130 \pm 90$ & $170 \pm 82$ & $<0.01$ \\
\hline $\mathrm{ARE}^{\dagger+t}[\mathrm{kU} / \mathrm{l}]$ & $126 \pm 63$ & $131 \pm 51$ & $115 \pm 56$ & $160 \pm 45$ & $215 \pm 73$ & $<0.01$ \\
\hline $\operatorname{stPON} 1^{t+t+}[\mathrm{U} / \mathrm{l}]$ & $324 \pm 213$ & $273 \pm 188$ & $294 \pm 211$ & $268 \pm 248$ & $438 \pm 318$ & $<0.01$ \\
\hline
\end{tabular}

${ }^{\star}(c)$ is higher than $(a, b, d, e),{ }^{* *}(d)$ is higher than $(a, b, c, e), \#(a)$ is higher than $(b, c, d, e),{ }^{\#}(a)$ is higher $(b, c, d, e), \# \#(a)$ is higher than $(a, b, d, e),{ }^{t, t+t+t,+t+t}(e)$ is higher than $(a, b, c, d)$.

ity of data distribution. In normally distributed groups the results were presented as mean and standard deviation (SD). Comparison of numerical variables between groups were performed using the Kruskal-Wallis and one-way ANOVA test, and post hoc comparisons were made using the Mann-Whitney $U$-test and $t$-test. The significance of the association between categorical variables was evaluated using the $\chi^{2}$ test. $P$-values less than 0.05 were accepted as significant.

\section{Results}

The HF patients were significantly older than other groups including the controls. All of the patients with STEMI were men; other groups were heterogeneous in gender without significant variations. PON1, ARE, and stPON1 levels were significantly lower in heart patients compared to the controls $(127 \pm 78,126 \pm 63,324 \pm 213$ for CABG; 119 $\pm 79,131 \pm 51,273 \pm 188$ for HVD; $110 \pm 74,115 \pm 56$, $294 \pm 211$ for HVD; $130 \pm 90,160 \pm 45,268 \pm 248$ for STEMI; $170 \pm 82,215 \pm 73,438 \pm 318$ for control, $p<$ 0.01 , respectively). The rate of smoking was similar between groups. Body mass index (BMI) was the highest in the HF patients, but did not differ significantly. When lipid panels were compared, TC, TG and LDL levels were highest in the CABG group. $\mathrm{HDL}$ levels were significantly higher in the control participants. The demographic and laboratory data are summarized in Table I.

The following phenotype distributions were found in the whole study population $(n=300)$ : QQ in 155 (51.7\%) subjects, QR in 124 (41.3\%) subjects and RR in 21 (7\%) subjects. Gene frequencies of patients were 0.697 and 0.302 ; those of controls were 0.775 and 0.225 for the $Q$ and $R$ alleles, respectively. The following phenotype distributions were found in the heart disease and con- trol groups: heart disease group ( $n=200): 48.5 \%$ (QQ), $42.5 \%(\mathrm{QR}), 9 \%$ (RR) and control group $(n=100): 58 \%(Q Q), 39 \%(Q R), 3 \%(R R) . R R$ (high activity) phenotypic distribution was more common in the heart disease groups than in controls $(p=0.04)$. $\mathrm{R}$ alleles were more common in heart disease patients than in controls, but the difference was not significant ( $p=0.14$ ) (Table II, Figure 2).

When the groups were compared separately, the phenotype distributions were as follows: CABG group: 41\% (QQ), 54\% (QR), 4\% (RR); HVD group: 57\% (QQ), 40\% (QR), 3\% (RR); HF: 51.4\% (QQ), $35,7 \%(\mathrm{QR}), 12.8 \%(\mathrm{RR})$; STEMI group: $50 \%(\mathrm{QQ})$, $33.3 \%(\mathrm{QR}), 16.7 \%(\mathrm{RR})$, and control group: $58 \%$ (QQ), 39\% (QR), 3\% (RR). RR (high activity) phenotypic distribution was more common in STEMI and HF than in the others $(p=0.01)$ (Table III).

A correlation study showed a strong positive correlation between the activities of StPON1/ARE and PON1 activity $(r=0.771, p<0.01)$, and a significant weak negative correlation between and

Table II. PON1 phenotype distribution of cardiac disease patients and healthy controls

\begin{tabular}{|c|c|c|c|}
\hline Phenotype & $\begin{array}{l}\text { Patients } \\
(n=200)\end{array}$ & $\begin{array}{l}\text { Control } \\
(n=100)\end{array}$ & $P$-value \\
\hline QQ & $97(48.5 \%)$ & $58(58 \%)$ & \multirow[t]{3}{*}{0.04} \\
\hline QR & 85 (42.5\%) & 39 (39\%) & \\
\hline RR & $18(9 \%)$ & $3(3 \%)$ & \\
\hline QQ & 97 (48.5\%) & $58(58 \%)$ & \multirow[t]{2}{*}{0.14} \\
\hline$Q R+R R$ & $103(51.5 \%)$ & $42(42 \%)$ & \\
\hline Q allele & 0.697 & 0.775 & \\
\hline $\mathrm{R}$ allele & 0.302 & 0.225 & \\
\hline
\end{tabular}

There were no significant differences between $Q Q$ phenotype and $Q R+R R$ phenotype, but $R R$ phenotype was significantly higher in cardiac disease patients ( $\chi^{2}$ test). 


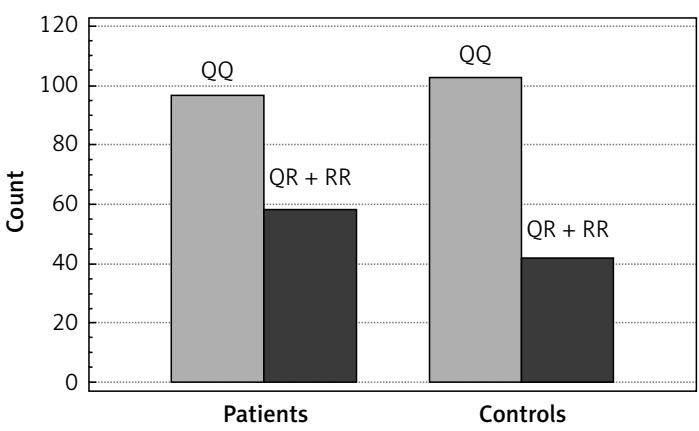

Figure 2. In terms of $\mathrm{O}$ and $\mathrm{R}$ alleles, the phenotype distribution between patients and controls. $\mathrm{R}$ alleles were more common in cardiac disease patients

stPON1/ARE and ARE activity $(r=-0.212, p<0.01)$ (Figure 3).

\section{Discussion}

Besides other things, our large control group is informative for PON1 phenotype distribution in the senior age Turkish population. In the entire study group, the frequency of the $\mathrm{Q}$ allele was 0.723 , and the frequency of the R allele was 0.277 (Figure 1). The frequency of the PON1 R allele in the current study was in line with previous studies carried out on this population. Our previous study revealed that the frequency of the $R$ allele in cancer patients was 0.28 [16]. Karakaya et al. [17] reported the $R$ allele frequency as 0.38 , and recently Bayrak et al. [18] reported a frequency of 0.26 . Aynacioglu et al. [19] genotyped 381 individuals and found the R allele frequency as 0.31 . In contrast to countries in the far-east where the RR phenotype distribution is high [20], these results indicated that the distribution of PON1 polymorphism in the Turkish population resembles other Caucasian populations.

When all four groups were taken together, the frequency of the $R$ allele $(Q R+R R)$ was higher in patients with cardiovascular disease compared to the control group, but the difference was not significant (Table II). On the other hand, the frequency of the RR phenotype was significantly higher. However, when the four patient groups were evaluated one by one, STEMI and HF groups differed from the CABG and HVD groups as well as controls with their significantly higher frequency of the RR phenotype. Actually, the RR phenotype frequency in CABG and HVD groups was almost identical to the control group. These findings made us question the adequacy of our combined CVD group. After all, it might be reasonable and more confirmative to consider all four groups separately. Actually, the high RR phenotype percentage in STEMI and HF patients was the most striking feature of this study.

Studies on the distribution of the PON1 phenotype in patients with cardiovascular disease have contradictory findings. For instance, in 2005 Rodríguez-Esparragon et al. [21] showed that PON1-Q was more important with regards to providing protection against lipid oxidation when compared

Table III. Comparison of groups individually

\begin{tabular}{|c|c|c|c|c|c|c|}
\hline Variable & $\begin{array}{c}\text { CABG } \\
(n=70)\end{array}$ & $\begin{array}{c}\text { HVD } \\
(n=30)\end{array}$ & $\begin{array}{c}\text { HF } \\
(n=70)\end{array}$ & $\begin{array}{c}\text { STEMI } \\
(n=30)\end{array}$ & $\begin{array}{c}\text { Control } \\
(n=100)\end{array}$ & $P$-value \\
\hline QQ & 29 (41\%) & 17 (57\%) & $36(51.4 \%)$ & 15 (50\%) & 58 (58\%) & \multirow[t]{3}{*}{0.01} \\
\hline QR & 38 (54\%) & 12 (40\%) & $25(35.7 \%)$ & $10(33.3 \%)$ & 39 (39\%) & \\
\hline $\mathrm{RR}$ & $3(4 \%)$ & $1(3 \%)$ & 9 (12.8\%) & 5 (16.7\%) & $3(3 \%)$ & \\
\hline$Q R+R R$ & 41 (59\%) & $13(43 \%)$ & 34 (48.6\%) & $15(50 \%)$ & 42 (42\%) & \\
\hline
\end{tabular}

Comparing STEMI and control, $p=0.02$; comparing HF and control, $p=0.04$. There were no significant differences in the PON1 phenotype distribution between other groups.

A

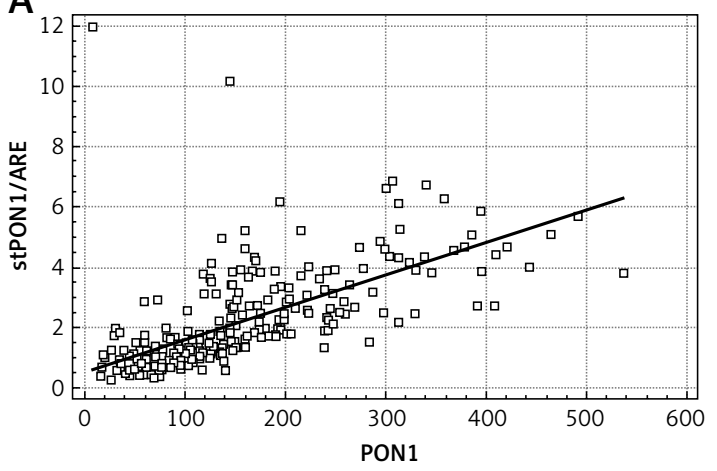

B

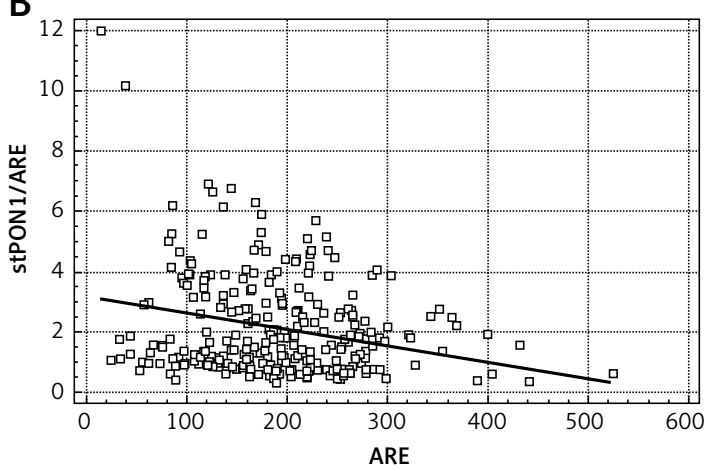

Figure 3. Graphics of correlations between stPON1/ARE and PON1 (A) and ARE (B). Strong positive correlations were observed between stPON1/ARE and PON1 activities $(r=0.771, p<0.01)$. Poor negative correlations were observed between stPON1/ARE and ARE $(r=-0.212, p<0.01)$ 
to PON1-R. One year later, Gaidukov et al. [22] demonstrated that the PON1-192R isoenzyme bound to HDL with higher affinity, showing higher stability and lipolactonase activity, and was more effective in HDL-mediated macrophage cholesterol efflux [22]. Despite the studies showing that low PON1 activity is a risk factor for cardiovascular and other diseases [4, 23], some studies have shown that the RR phenotype and high PON1 activity have a closer relationship to cardiovascular disease [20]. There are studies from before the year 2000 which failed to find a relationship between polymorphism of the human paraoxonase gene and risk of AMI or CAD [24, 25].

Known PON1 functions include atheroprotective activity, esterase activity, peroxidase activity, cholesterol transport, antioxidant activity, antiplatelet activity, and lactonase and thiolactonase activity [4, 26-28]. It is impressive that this single enzyme carries out so many reactions. We believe that PON1 is not a single enzyme, but a multiple enzyme system.

PON1 is a versatile enzyme that shows genetic variation among different ethnic groups, and shows individual variations in its function. Previous studies on how this phenotypic variety affects the other features of PON1 can be summarized as follows: esterase activity, $\mathrm{Q}>\mathrm{R}$ [14]; lipolactonase activity, $\mathrm{Q}=\mathrm{R}$ [29] or $\mathrm{R}>\mathrm{Q}$ [22]; antioxidant activity, $\mathrm{R}>\mathrm{Q}$ [30]; and thiolactonase, $\mathrm{Q}>\mathrm{R}$ [18]. Although the antioxidant feature is higher in the $\mathrm{R}$ allele, the incidence of cardiovascular disease is higher in individuals carrying this allele. On the other hand, another important finding is that individuals carrying the $\mathrm{Q}$ allele have higher thiolactonase activity [18]. Thiolactone is a thioester of homocysteine; and homocysteine is a risk factor for cardiovascular disease [26]. Lower thiolactonase activity of the PON1 enzyme system in individuals carrying the $\mathrm{R}$ allele might explain the higher incidence of cardiovascular disease in these individuals.

Another effect of salt on the PON1 enzyme system is the inhibition of ARE [29]. Previous studies have shown that ARE can be a precursor for the anti-atherosclerotic features of the PON1 enzyme system. Tang et al. [31] have shown that low ARE activity has a high prognostic value for cardiovascular disease. Here, the actual puzzle is the physiological importance of ARE inhibition by salt. There are no previous studies in this area. In particular, how changes in the physiological and pathological salt load and changes in the aldosterone-renin-angiotensin system affect the PON1 enzyme system is unknown. Increasing the salt load induces the esterase activity of PON1 [32, 33], which in turn suppresses ARE. The formation of free radicals due to increased esterase activity of PON1 cannot be removed by ARE, and this could explain the underlying molecular mechanism. This theory may solve the ongoing debate on the phenotypic distribution of PON1 in cardiovascular disease. In addition, this theory can be validated mathematically. The increasing salt load stimulates PON1, which leads to the suppression of ARE; and the increase in the stPON1/ARE ratio can lead to a phenotypic shift. In this study, the positive correlation between the stPON1/ARE ratio and $P O N 1$, and the negative correlation between the stPON1/ARE ratio and ARE, support this theory (Figure 3). However, further studies are required to support this theory.

In conclusion, we found a higher percentage of RR phenotype in STEMI and HF patients compared to a large control group as well as compared to two other groups of cardiac disease patients. Considering the relationship between CABG vs. STEMI and HVD vs. HF, this finding may have serious clinical consequences. The severity of inflammation in the patients with HF and STEMI may be more severe than in the patients with CABG and HVD. These changes in the severity of the inflammation may cause the phenotypic shift. Obviously, further studies investigating the relationship between the PON1 enzyme system and cardiovascular disease are required.

\section{Conflict of interest}

The authors declare no conflict of interest.

\section{References}

1. Perk J, Graham I, De Backer G. Prevention of cardiovascular disease: new guidelines, new tools, but challenges remain. Heart 2014; 100: 675-7.

2. Lozano R, Naghavi M, Foreman K, et al. Global and regional mortality from 235 causes of death for 20 age groups in 1990 and 2010: a systematic analysis for the Global Burden of Disease Study 2010. Lancet 2012; 380: 2095-128.

3. Anderson RN, Smith BL. Deaths: leading causes for 2002. Natl Vital Stat Rep 2005; 53: 1-89.

4. Eren E, Yilmaz N, Aydin O. High density lipoprotein and it's dysfunction. Open Biochem J 2012; 6: 78-93.

5. Otocka-Kmiecik A, Mikhailidis DP, Nicholls SJ, Davidson M, Rysz J, Banach M. Dysfunctional HDL: a novel important diagnostic and therapeutic target in cardiovascular disease? Prog Lipid Res 2012; 51: 314-24.

6. Ursoniu S, Sahebkar A, Serban MC, Banach M. Lipid profile and glucose changes after supplementation with astaxanthin: a systematic review and meta-analysis of randomized controlled trials. Arch Med Sci 2015; 11: 253-66.

7. Ellidag HY, Eren E, Aydin O, Yıldırım M, Sezer C, Yilmaz N. Multiple myeloma: relationship to antioxidant esterases. Med Princ Pract 2014; 23: 18-23.

8. Li P, Bu SH, Lu XT, et al. Relationships between PON1 Q192R polymorphism and clinical outcome of antiplatelet treatment after percutaneous coronary intervention: a meta-analysis. Mol Biol Rep Mol Biol Rep 2014; 41: 6263-73. 
9. Humbert R, Adler DA, Disteche CM, Hassett C, Omiecinski CJ, Furlong CE. The molecular basis of the human serum paraoxonase activity polymorphism. Nat Genet 1993; 3: 73-6.

10. Lurie G, Wilkens LR, Thompson PJ, et al. Genetic polymorphisms in the paraoxonase 1 gene and risk of ovarian epithelial carcinoma. Cancer Epidemiol Biomarkers Prev 2008; 17: 2070-7.

11. Dai-Hua F, Cong-Hai F, Qiang J, Bo-Xiang Q, Juan L, Lu W. Differential effects of paraoxonase 1 (PON1) polymorphisms on cancer risk: evidence from 25 published studies. Mol Biol Rep 2012; 39: 6801-9.

12. Aviram M, Hardak E, Vaya J, et al. Human serum paraoxonases (PON1) Q and R selectively decrease lipid peroxides in human coronary and carotid atherosclerotic lesion: PON1 esterase and peroxidase-like activities. Circulations 2000; 101: 2510-7.

13. Mahrooz A, Alizadeh A, Gohari G. The salt stimulation property of serum paraoxonase (PON1) could be a valuable factor in evaluating the enzyme status in ischemic stroke: the role of activity-determined PON1 192Q/R phenotypes. J Neurol Sci 2014; 338: 197-202.

14. Eckerson HW, Wyte MC, LaDu BN. The human serum paraoxonase/arylesterase polymorphism. Am J Hum Genet 1983; 35: 1126-38.

15. Haagen L, Brock A. A new automated method for phenotyping arylesterase (E.C.3.1.1.2.) based upon inhibition of enzymatic hydrolysis of 4-nitrophenyl acetate. Eur J Clin Chem Clin Biochem 1992; 30: 391-5.

16. Ellidag HY, Eren E, Aydin O, Neselioglu S, Yilmaz N. The phenotype distribution of paraoxonase- 1 in patients with multiple myeloma, bladder, and colorectal cancer. J Med Biochem 2014; 33: 252-8.

17. Karakaya A, Ibiş S, Kural T, Köse SK, Karakaya AE. Serum paraoxonase activity and phenotype distribution in Turkish subjects with coronary heart disease and its relationship to serum lipids and lipoproteins. Chem Biol Interact 1999; 118: 193-200.

18. Bayrak A, Bayrak T, Demirpençe E, Kılınç K. Differential hydrolysis of homocysteine thiolactone by purified human serum (192)Q and (192)R PON1 isoenzymes. J Chromatogr B Analyt Technol Biomed Life Sci 2011; 879: 49-55.

19. Aynacioglu AS, Cascorbi I, Mrozikiewicz PM, Nacak M, Tapanyigit EE, Roots I. Paraoxonase 1 mutations in a Turkish population. Toxicol Appl Pharmacol 1999; 157: 174-7.

20. Wang M, Lang X, Zou L, Huang S, Xu Z. Four genetic polymorphisms of paraoxonase gene and risk of coronary heart disease: a meta-analysis based on 88 case-control studies. Atherosclerosis 2011; 214: 377-85.

21. Rodríguez-Esparragón F, Rodríguez-Pérez JC, HernándezTrujillo $Y$, et al. Allelic variants of the human scavenger receptor class $B$ type 1 and paraoxonase 1 on coronary heart disease: genotype-phenotype correlations. Arterioscler Thromb Vasc Biol 2005; 25: 854-60.

22. Gaidukov L, Rosenblat M, Aviram M, Tawfik DS. The 192R/Q polymorphs of serum paraoxonase PON1 differ in HDL binding, lipolactonase stimulation, and cholesterol efflux. J Lipid Res 2006; 47: 2492-502.

23. Gluba A, Pietrucha T, Banach M, Piotrowski G, Rysz J. The role of polymorphisms within paraoxonases (192 Gln/Arg in PON1 and 311Ser/Cys in PON2) in the modulation of cardiovascular risk: a pilot study. Angiology 2010; 61: 157-65.

24. Herrmann SM, Blanc H, Poirier O, et al. The Gln/Arg polymorphism of human paraoxonase (PON 192) is not related to myocardial infarction in the ECTIM study. Atherosclerosis 1996; 126: 299-303.

25. Antikainen M, Murtomaki S, Syvanne M, et al. The GlnArg192 polymorphism of the human paraoxonase gene (HUMPONA) is not associated with the risk of coronary artery disease in Finns. J Clin Invest 1996; 98: 883-5.

26. Yilmaz N. Relationship between paraoxonase and ho mocysteine: crossroads of oxidative diseases. Arch Med Sci 2012; 8: 138-53.

27. Eren E, Ellidag HY, Aydin O, Yılmaz N. Homocysteine, paraoxonase-1 and vascular endothelial dysfunction: omnibus viis Romam Pervenitur. J Clin Diagn Res 2014; 8: CE01-4.

28. Ellidag HY, Aydin O, Eren E, Yilmaz N, Ergin M. Decreased HDL-dependent paraoxonase and arylesterase enzyme activity may indicate a worse prognosis in multiple myeloma. Asian Pac J Cancer Prev 2014; 15: 9847-51.

29. Beltowski J, Wojcicka G, Marciniak A. Species-and substrate-specific stimulation of human plasma paraoxonase 1 (PON1) activity by high chloride concentration. Acta Biochim Pol 2002; 49: 927-36.

30. Otocka-Kmiecik A, Orłowska-Majdak M. The role of genetic (PON1 polymorphism) and environmental factors, especially physical activity, in antioxidant function of paraoxonase. Post Hig Med Dosw 2009; 63: 668-77.

31. Tang WH, Hartiala J, Fan Y, et al. Clinical and genetic association of serum paraoxonase and arylesterase activities with cardiovascular risk. Arterioscler Thromb Vasc Biol 2012; 32: 2803-12.

32. Gluba A, Banach M, Mikhailidis DP, Rysz J. Genetic determinants of cardiovascular disease: the renin-angiotensin-aldosterone system, paraoxonases, endothelin-1, nitric oxide synthase and adrenergic receptors. In Vivo 2009; 23: 797-812.

33. Kasprzak MP, Iskra M, Majewski W, et al. PON1 status evaluation in patients with chronic arterial occlusion of lower limbs due to atherosclerosis obliterans. Arch Med Sci 2014; 10: 1101-8. 